\title{
Paradoxical lipodystrophic changes due to conventional bovine and highly purified porcine/bovine insulins
}

\author{
I. W. CAMPBELL \\ M.B., F.R.C.P. (Edin.)
}

\author{
C. DUNCAN \\ M.B., Ch.B.
}

\author{
A. R. ANANI \\ M.B., Ch.B. \\ Medical Unit, Victoria Hospital, Kirkcaldy, Fife, KY2 5AH, Scotland
}

\begin{abstract}
Summary
A 78-year-old woman developed marked insulin lipoatrophy due to conventional bovine insulin injected into the upper limbs. Changing to a combination of highly purified porcine/bovine insulins injected into the lower limbs resulted in the opposite effect, namely insulin-induced lipohypertrophy. Use was then made of this effect by injecting the highly purified insulins into the atrophied upper limb injection sites with resultant improvement in these wasted areas over the next 10 months.
\end{abstract}

KEY WORDS: lipoatrophy, lipohypertrophy, diabetes mellitus.

\section{Introduction}

Insulin-induced lipodystrophy may present in two ways: either as lipoatrophy with disappearance of subcutaneous tissue, or lipohypertrophy with lipomatous change at the injection site (Krall and Zorrilla, 1971). A recent study showed that in patients injecting conventional bovine insulin $16 \%$ had evidence of lipoatrophy and $14 \%$ of lipohypertrophy at injection sites, whereas in those injecting highly purified porcine insulin $22 \%$ had evidence of lipohypertrophy but in no case was there evidence of lipoatrophy (Young et al., 1981). A patient is described in whom conventional bovine insulin first caused lipoatrophy at the injection sites in both upper limbs; a combination of highly purified porcine and bovine insulins then caused lipohypertrophy in the lower limb insulin injection areas; finally, the lipatrophy was managed successfully by injecting the highly purified insulins into the atrophied regions in the upper limbs.

\section{Case report}

A 78-year-old female first presented when aged 70 years in hyperosmolar non-ketotic coma. Insulin injection BP (soluble) was given intravenously at this stage for $24 \mathrm{~h}$ during the treatment of the acute metabolic decompensation, but for the next 5 years her diabetes mellitus was controlled with a carbohydrate-restricted diet and chlorpropamide $375 \mathrm{mg}$ daily together with metformin $1 \mathrm{~g}$ twice daily. The patient was then admitted in diabetic ketoacidosis precipitated by a urinary tract infection. At this time after intravenous treatment with soluble insulin she was commenced on insulin treatment with a once daily regime of 32 units insulin injection BP (soluble) and 44 units protamine zinc insulin (Wellcome), the injections being administered each day repeatedly into the same site in the lateral aspect of the upper limbs by the district nurse as the patient had dementia due to cerebral arteriosclerosis.

During the next 3 years, the nurse injected the conventional bovine insulins only into both upper limbs, alternating between right and left. It was noted that both injection sites showed marked lipoatrophy (Fig. 1a), which on further enquiry had been present for 1 year. The patient was changed to a combination of highly purified porcine and bovine insulins, namely 16 units Actrapid MC and 40 units Ultratard MC (Novo), again injected by the district nurse. Although it had been intended to treat the atrophied sites by injecting the purified insulins into the same area, the insulins were in fact only injected each day into the lateral aspect of both upper thighs, whereupon after 4 months marked lipohypertrophy had occurred at these sites giving the appearance of large lipomas (Fig. 1b). The highly purified porcine (Actrapid MC) and bovine (Ultratard MC) insulins were now injected directly into the atrophied sites in the upper limbs.

After a further 10 months, these areas had much improved (Fig. 1c) and the hypertrophied areas in the thighs had receded (Fig. 1d). 

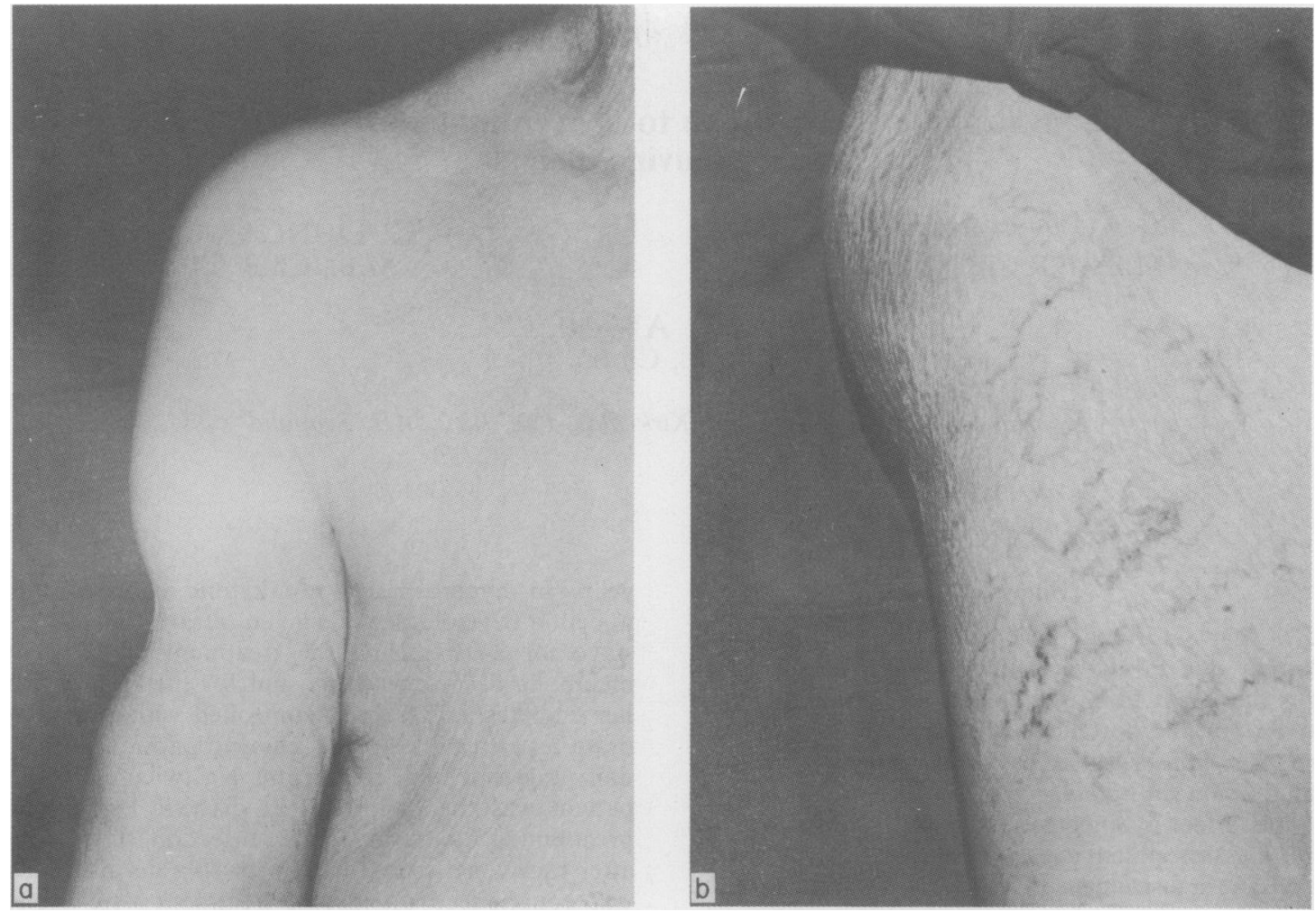

FIG. 1. (a) Severe lipoatrophy in right upper limb caused by injection of soluble and protamine zinc insulins. (b) Marked lipohypertrophy right upper thigh, giving appearance of large lipoma, caused by injection of Actrapid MC and Ultratard MC insulins.

\section{Discussion}

For many years after the introduction of insulin, it was believed that insulin lipoatrophy or lipohypertrophy occurred in susceptible individuals regardless of the type of insulin given and that both changes in some way were due to a local metabolic effect of insulin (Krall and Zorrilla, 1971). However, lipoatrophy, variably reported in 10-55\% of patients treated with conventional bovine insulins, has recently been attributed to local immune complex formation, complement fixation and release of lysosomal enzymes in response to a presumed antigenic component of these less purified insulins (Reeves, Allen and Tattersall, 1980). There is then a resultant loss of subcutaneous fat. Lipoatrophy is virtually specific for conventional bovine insulins and only caused rarely by highly purified insulin (Jones et al., 1981).

Less is known about the exact mechanism of insulin hypertrophy which is often less well recognized by patients than atrophic changes. Thus, hypertrophy may be more common than previously appreciated and in a recent study was reported in $22 \%$ of patients treated with highly purified porcine insulin compared with $14 \%$ in patients treated with conventional bovine insulins (Young et al., 1981).

It was previously believed that lipohypertrophy was due to the local anabolic effect of insulin in promoting fat and protein synthesis (Renold, Marble and Fawcett, 1950). Whilst this is still felt to be the case, there is probably a variability in the sensitivity of subcutaneous fatty tissue to insulin, not only between individuals but possibly also at various sites in the same patient (Meier, Weerakoon and Dandona, 1982). As in our case, appreciable lipomatous change may occur with highly purified insulin (Wright et al., 1979). It is probably not the dose of insulin injected at the site which is important in producing hypertrophy, but rather the constant injecting into the same area as bilateral abdominal lipohypertrophy has been reported after continuous low-dose subcutaneous infusion of insulin (Meier $e t$ al., 1982).

The case described illustrates that the mechanism of insulin lipodystrophy is still not clear. Repeated injections in the same individual of conventional bovine insulins into the same area produced marked 

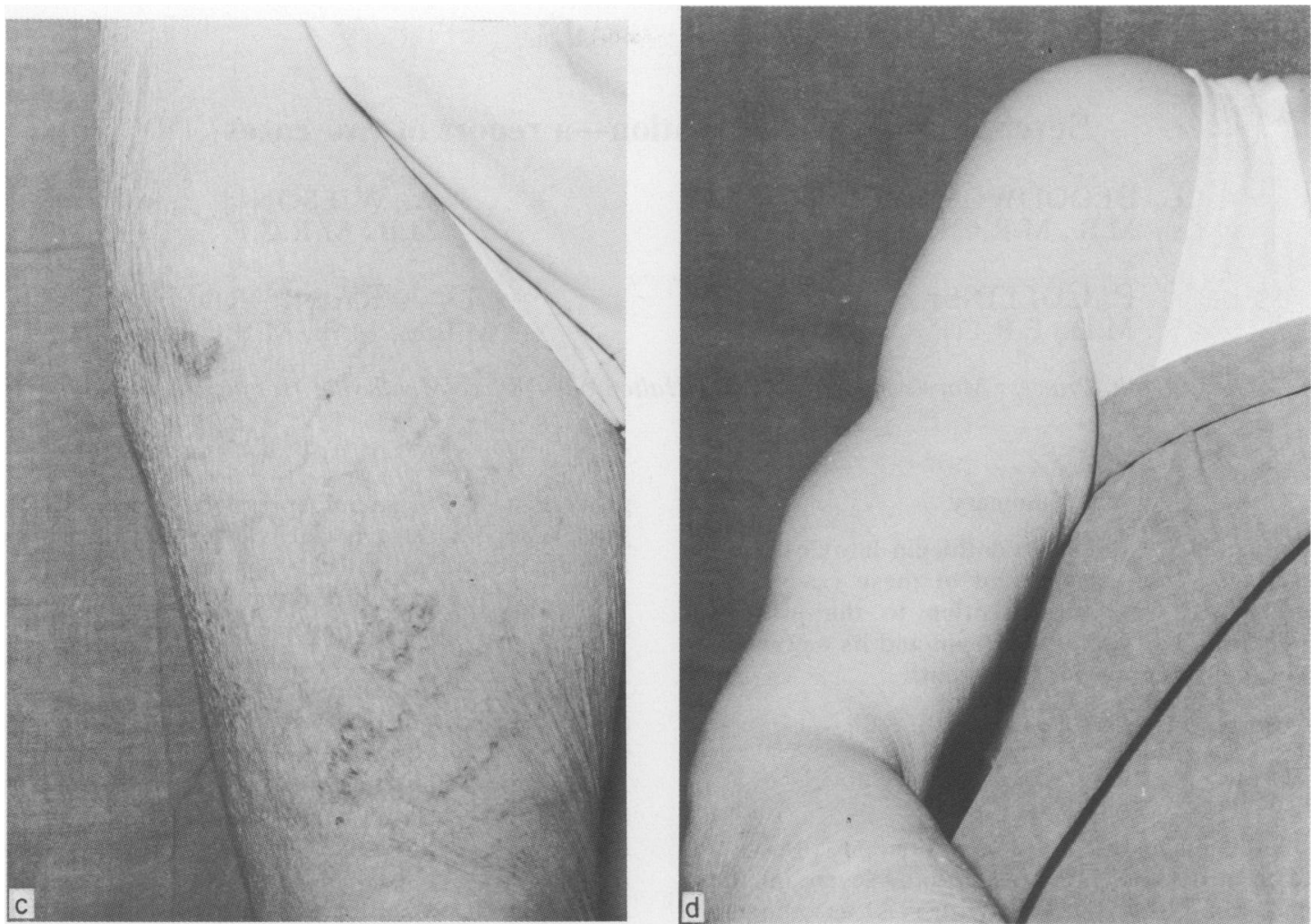

FIG. 1. (c) Improvement in lipoatrophy after 10 months of injection of Actrapid MC and Ultratard MC insulins into the atrophied areas.

(d) Resolution of lipohypertrophy 10 months after Actrapid MC and Ultratard MC injections had been avoided at this site.

lipoatrophy, whereas repeated injection of highly purified insulin, containing both porcine and bovine insulins, caused marked lipohypertrophy and use was made of the latter effect to treat successfully the insulin atrophy in the upper limb. It is our policy to treat patients with lipoatrophy induced by conventional bovine insulin by changing to highly purified porcine, or bovine, insulins as has been described previously (Teuscher, 1974). Indeed, local treatment with highly purified porcine insulin has been used in a non-diabetic to treat successfully a vaccination scar with soft-tissue atrophy (Amroliwalla, 1977).

\section{Acknowledgments}

We thank Miss H. Clark, Mr G. McLaren and Mr W. R. D. MacIntyre of the Medical Photography Department for the figures, and Mrs M. Frew for secretarial help.

\section{References}

AMroliwalla, F.K. (1977) Vaccination scar with soft-tissue atrophy restored by local insulin treatment. British Medical Journal, 1, 1389.
Jones, G.R., Statham, B., OWEns, D.R., Jones, M.K. \& Hayes, T.M. (1981) Lipoatrophy and monocomponent porcine insulin. British Medical Journal, 282, 190.

KRALL, L.P. \& ZoRRILla, E. (1971) Disorders of the skin in diabetes. In: Joslin's Diabetes Mellitus (Eds. A. Marble, P. White, R.F. Bradley and K.P. Krall), 11 th ed., p. 653. Lea \& Febiger, Philadelphia.

Meier, A., Weerakoon, J. \& Dandona, P. (1982) Bilateral abdominal lipohypertrophy after continuous subcutaneous infusion of insulin. British Medical Journal, 285, 1539.

Reeves, W.G., Allen, B.R. \& Tattersall, R.B. (1980) Insulininduced lipoatrophy: evidence for an immune pathogenesis. British Medical Journal, 280, 1500.

RENOLD, A.E., MARBle, A. \& FAwCETt, D.W. (1950) Action of insulin on deposition of glycogen and storage of fat in subcutaneous tissue. Endocrinology, 46, 55.

TEUSCHER, A. (1974) Treatment of insulin lipoatrophy with monocomponent insulin. Diabetologia, 10, 211.

Wright, A.D., Walsh, C.H., FitzGerald, M.C. \& MALINS, J.M. (1979) Very pure porcine insulin in clinical practice. British Medical Journal, 1, 25.

Young, R.J., STEel, J.M., FrIER, B.M. \& DUNCAN, L.J.P. (1981) Insulin injection sites in diabetes-a neglected area? British Medical Journal, 283, 349.

(Accepted 4 May 1983) 